\title{
Inhibition Mechanism of LDHs on Coal Spontaneous Combustion Based on Thermogravimetric Analysis
}

\author{
Wenyong $\operatorname{Liu}^{1,2,3}, \mathrm{Hu} \mathrm{Wen}^{1,2,3^{*}}$, Jun Guo ${ }^{1,2,3}$ \\ ${ }^{1}$ Xi'an University of Science and Technology School of safety science and Engineering, Xi'an 710054, China \\ ${ }^{2}$ Shaanxi Key Laboratory of Prevention and Control of Coal Fire, Xi'an 710054, China \\ ${ }^{3}$ National Mine Emergency Rescue (Xi'an) Research Center, Xi’an 710054, China
}

Corresponding Author Email: wenh@xust.edu.cn

https://doi.org/10.18280/ijht.370229

Received: 8 January 2019

Accepted: 20 March 2019

\section{Keywords:}

LDHs, coal spontaneous combustion, inhibition mechanism, thermal gravimetric analysis, characteristic temperature point

\begin{abstract}
The technology of preventing and controlling coal spontaneous combustion by paralysant is one of the most important technologies in coal spontaneous combustion prevention and control system, especially the layered double hydroxide (LDHs) developed in recent years is a new type of coal spontaneous combustion inhibitor. In order to study the inhibition effect of LDHs on coal spontaneous combustion and the best ratio (the most economical and efficient addition), this paper uses self-made LDHs inhibitor preparation device to successfully make the LDHs in a variety of metal ion ratios by coprecipitation method. And then, the paper uses the thermal gravimetric analysis to obtain the TD-DTG curves of coal samples at $3 \%, 5 \%$, $10 \%$ and $15 \%$ by 5 kinds of LDHs additive amounts, and then, the inhibition effect of various inhibitors under different adding conditions is investigated. The results show that when the LDHs physical mixing amount is $15 \%$, it can effectively prevent the spontaneous combustion of coal samples; finally, according to the test results, the hypothesis of LDHs inhibiting coal spontaneous combustion mechanism is put forward, that is, on the one hand, the $\mathrm{La}^{3+}$ in LDHs will have complexation effect with active groups in coal to prevent the reaction of coal and oxygen; on the other hand, the intermediate bound water between rare earth layered double hydroxides will increase with the adding of $\mathrm{La}^{3+}$, so as to restrain the spontaneous combustion of coal by self-heating. The research findings will have better theoretical guidance and reference significance for the study on LDHs new type self-ignition inhibitor and its on-site economical and efficient use.
\end{abstract}

\section{INTRODUCTION}

Coal is the main body of energy in China, which accounts for $70 \%$ of the primary energy development and consumption in China [1-3], its dominance will remain unchanged for a long time. However, China's coal spontaneous combustion is very serious, and over $90 \%$ coal mines in China have self-ignition, the number of annual coal spontaneous combustion disasters is over 4000 times [4-5]. The coal spontaneous combustion will not only occur during the mining process, but also during ground storage and transportation [6-7].

At present, coal spontaneous combustion prevention and control technology is relatively mature, and it has formed a certain system. The inhibitor is one of the fire prevention and control materials with good anti fire performance, and domestic and foreign scholars have done a lot of researches in this area. Many scholars had adopted fire performance test and other means to study the $\mathrm{MgCl}_{2}, \mathrm{CaCl}_{2}, \mathrm{ZnCl}_{2}, \mathrm{Na}_{2} \mathrm{CO}_{3}$ and other inhibitors, activation energy, activation center, and other theories to analyze the resistance mechanism of the inhibitor to each ranking coal, thus the economical and efficient concentration of inhibitor and its inhibition efficiency had been gained [8-13]. Also, Xu [14] had studied the structure, performance, fire extinguishing technology and its application in coal mine of fly ash colloid made from the hybrid reaction of base material A, coagulant B, fly ash and water. Deng et al.
[6] had designed a new type of FSA microporous colloidal flame retardant. Deng and Xu [15] had added a special additive into the flame retardant to make multiviscosity of water (or mud) to form a novel composite colloid flame retardant. What's more, scholars have also studied out the new polyvinyl alcohol oxygen barrier gel inhibitor [16], inorganic foaming cementing material [17], sodium silicate, polyelectrolyte composite gel inhibitor [18] and other coal spontaneous combustion resistance materials.

Layered Double Hydroxides (LDHs), known as anionic clay, it is a kind of inorganic crystal material with exchangeable anion between layers [19]. In recent years, a large number of studies have showed that the material is a kind of material found which can make polymer materials have good flameretardant performance. And it has the advantages of less additive amount, little influence on the mechanical properties of the material, heat release rate decreased significantly, no pollution, less smoke, [20-23]. LDHs is a kind of flame retardant polymer materials that can be integrated with other flame retardant complex, it is one of the main research directions of LDHs applied in polymer flame retardant, and it has obtained a series of research results. For example, the research group of Marquette University had systematically studied the influence law of types of anions, types of metal ions and organic modification on the nano dispersion morphology and flame-retardant effect of LDHs in PMMA. 
Zhao Yun et al had added the Nano sized Mg/Al-LDHs into epoxy resin to prepare composite. Results had showed that it would show significant smoke suppression effect when the Nano LDHs addition was at $0.20 \%-0.60 \%$ range. Zheng Xiuting et al. had studied that it could make the maximum smoke density declined to $30 \%$ when the LDHs addition was at $3 \%-5 \%$, LDHs had no adverse effect on the mechanical properties of PVC. Nevertheless, would improve the tensile strength and elongation at break, and also the thermal stability of the material [24-25].

Thermogravimetric analyzer has the advantages of high precision, convenient test and good repetitiveness, it has been the often-used experimental means by many research institutions at domestic and abroad to analyze the characteristics of coal spontaneous combustion and coal oxidation process [26]. Zhang [27] had carried out thermogravimetric experiment on the thermal decomposition process of coal, which explored the effect of coal size and coal sample size on thermal decomposition of coal, And the dynamics study on the thermal decomposition reaction of coal determined the kinetic equation of the reaction. What's more, the parameters of thermal decomposition kinetic equation have been calculated. Wu and Chen [28] adopted the thermal analyzer to obtain the essence of coal spontaneous combustion process by thermal analysis simulation experiment, which approved that the coal spontaneous combustion was a process of coal self-oxidation acceleration, and the oxidation rate of coal was too fast, because the heat generated by oxidation could not spread to the outside, thus, it led to the spontaneous combustion of coal.

In this paper, the multiple synthetic LDHs inhibitors are used, and the coal sample from a coal mine in Inner Mongolia is taken as the tested sample. The thermal gravimetric analysis technology is used to analyze the resistance characteristics of these LDHs inhibitors to spontaneous combustion of coal samples under different concentrations to gain the optimal resistance ratio. Therefore, the study on the coal spontaneous combustion prevention and control and coal spontaneous combustion inhibitor in this mine has important theoretical value and research significance.

\section{EXPERIMENTAL PRINCIPLES AND CONDITIONS}

\subsection{Experimental principles}

The principle of thermogravimetric analyzer is to collect the experimental data by computer setting program based on the experimental conditions, the changes of quality of coal samples with temperature changes during the weightlessness process were recorded, then the thermogravimetric curve (TG curve) was drawn, meanwhile, the weight loss rate curve (DTG curve) can be gained if differential is carried out on the TG curve, that is, the instantaneous weight loss rate can be calculated according to TG curve [29]. Among them, the TG curve reflects the weight changes during the process of coal oxidation, and the change of coal weight is the result of the complex between coal and oxygen and desorption and escape of various gases, the DTG curve reflects the relationship between compound rate of coal and oxygen and producing rates of various gas [30]. The characteristics of these two curves reflect the reaction conditions of coal samples, and the process of curve change is the external performance of the whole reaction process. Therefore, the spontaneous combustion degree of coal samples can be obtained indirectly by analyzing the curves.

\subsection{Experimental preparation and process}

\subsubsection{Preparation of inhibitor for experiment}

1) Preparation device of LDHs inhibitor

The common preparation methods of LDHs inhibitor include coprecipitation, nucleation / crystallization isolation, template synthesis, roasting reduction, ion exchange, urea, etc. In this paper, the coprecipitation is used to prepare the rare earth layered double hydroxide with different metal ion ratios. And the adopted device is shown in Figure 1.

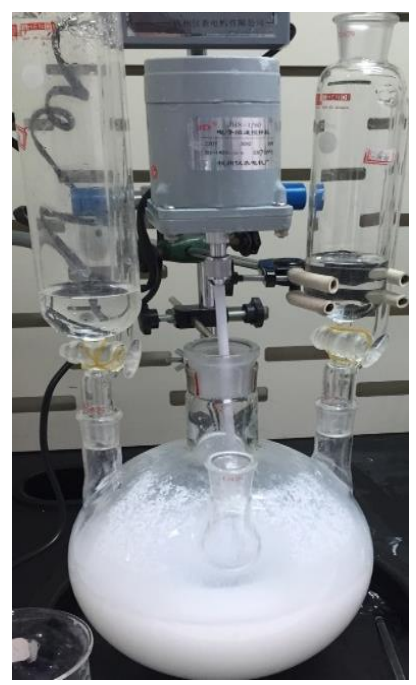

Figure 1. Preparation device of LDHs inhibitor

\section{2) Preparation process}

The preparation process of LDHs inhibitor can be divided into 4 steps of mixing, crystallization, washing and drying, as shown in the Figure 2.

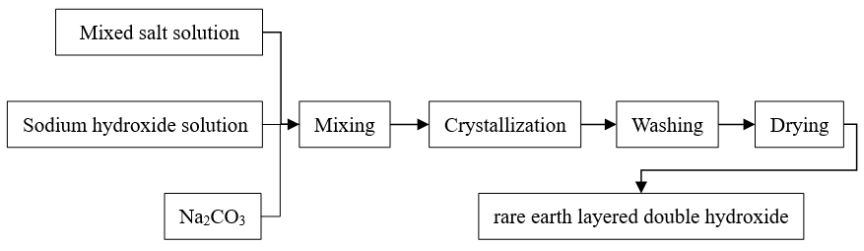

Figure 2. Preparation flow chart of rare earth layered double hydroxide

(1) Mixing: Europium nitrate, lanthanum nitrate, magnesium nitrate, zinc nitrate and aluminum nitrate are taken as raw materials to prepare the metal ion salt solution with 0.20 $\mathrm{mol} / \mathrm{L}$ concentration. $2000 \mathrm{~mL}$ mixed salt solution $\left(\mathrm{n}\left(\mathrm{La}^{3+}\right) / \mathrm{n}\right.$ $\left.\left(\mathrm{Zn}^{2+}\right) / \mathrm{n}\left(\mathrm{Mg}^{2+}\right) / \mathrm{n}\left(\mathrm{Al}^{3+}\right)=1.5: 1.5: 1\right)$ is added into the 5000 $\mathrm{mL}$ four mouth flask, and $1500 \mathrm{~mL}$ Mixed alkali solution $(\mathrm{C}$ $\left.\left(\mathrm{OH}^{-}\right) / \mathrm{C}\left(\mathrm{CO}_{3}{ }^{2-}\right)=2.25, \mathrm{C}\left(\mathrm{OH}^{-}\right)=0.75 \mathrm{~mol} / \mathrm{L}\right)$ is dropped by drop for titration with mixed salt solution, quickly mixing, and the $\mathrm{pH}$ value of titration end point is controlled at 9.0-11.0, after titration, continuing to stir it for $60 \mathrm{~min}$ under ultrasonic action.

(2) Crystallization: pouring the mixed solution into the beaker and marking. Then, placing it under $70{ }^{\circ} \mathrm{C}$ water bath microwave effect for crystallization, after $20 \mathrm{~h}$, taking out.

(3) Washing: taking out the product from water bath, then 
using de ionized water centrifuge to wash till no $\mathrm{NO}^{3-}$.

(4) Drying: the washed product shall be placed into vacuum drying oven, the temperature shall be set at $75^{\circ} \mathrm{C}$ for drying for continuous $24 \mathrm{~h}$, then taking out and grinding to get rare earth layered double hydroxide.

The products obtained in this experiment and the ratio of each metal ions shown in Table 1. Each product yield is about 30-45 g. According to the experimental needs, repeat the above synthetic experiment.

Table 1. The ratio of metal ions in each LDHs

\begin{tabular}{ccc}
\hline $\begin{array}{c}\text { Name of rare earth layered } \\
\text { double hydroxide }\end{array}$ & $\begin{array}{c}\text { Metal ion } \\
\text { ratio }\end{array}$ & Proportion \\
\hline LDHs-1 & & $0.0: 1.5: 1.5: 1.0$ \\
LDHs-2 & & $0.1: 1.5: 1.5: 0.9$ \\
LDHs-3 & $\mathrm{La}^{3+}: \mathrm{Mg}^{2+}:$ & $0.3: 1.5: 1.5: 0.7$ \\
LDHs-4 & $\mathrm{Zn}^{2+}: \mathrm{Al}^{3+}$ & $0.5: 1.5: 1.5: 0.5$ \\
LDHs-5 & & $0.7: 1.5: 1.5: 0.3$ \\
LDHs-6 & & $0.9: 1.5: 1.5: 0.1$ \\
\hline
\end{tabular}

\subsubsection{Experimental conditions and process}

TG209 thermogravimetric analyzer of NETZSCH Company, as shown in Figure 3, is used as experimental equipment. The candle coal of Inner Mongolia coal mine is used as sample, which is ground into pulverized coal with the particle size of $0.098 \mathrm{~mm}$. And $1 \mathrm{~g}$ coal sample is taken for each time to be mixed with rare earth layered double hydroxides LDHs-1, LDHs-2, LDHs-3, LDHs-4, LDHs-5 at different adding amount $(3 \%, 5 \%, 10 \%, 15 \%)$, then, the mixed samples is fully ground in agate mortar to make it to be homogeneous mixture. Then, place it into silica gel drying box.

For each sample, $10 \mathrm{mg}$ is taken into the sample room of the thermogravimetric tester for testing at each time. The experiment uses non isothermal thermogravimetry, the temperature rises from $20{ }^{\circ} \mathrm{C}$ to around $800{ }^{\circ} \mathrm{C}$ with a heating rate of $10{ }^{\circ} \mathrm{C} / \mathrm{min}$. The oxygen concentration (volume ratio) is $21 \%$. Then, the DSC, TG curves of tested coal samples can be obtained.

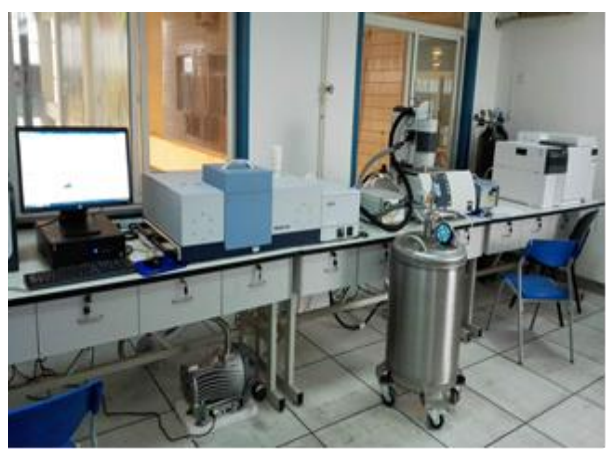

Figure 3. Thermal gravimetric analyzer

\section{EXPERIMENTAL RESULTS AND ANALYSIS}

According to the principle of mechanism and characteristics of coal spontaneous combustion tested by thermogravimetric, different characteristic points of thermogravimetric curves were analyzed (peak point on the curve), then, the length of time used for rapid weightlessness and maximum weight loss rate and other indicators can be used to analyze the complete process of oxidation and spontaneous combustion of coal in coal burning [31]. A series of experimental results show that different experimental conditions can lead to the difference of the thermal characteristic temperature value and thermal mass loss rate. However, the total reaction process is similar, meaning the curve is similar in line and can find characteristic temperature points on each curve.

\subsection{Natural characteristic temperature of raw coal samples in Selian mine}

The structure of coal has remarkable complexity and diversity, and the activity of different structural units on the surface of coal molecule is also different. In the process of coal spontaneous combustion, structural unit with different activity in coal can participate in low temperature oxidation at a given temperature, while in the thermal weight curve, it shows that the weight loss and thermal loss rate of coal samples are different at this temperature. Therefore, the characteristic temperature points in the process of coal spontaneous combustion can be studied by thermogravimetric analysis. By comparing the change of characteristic temperature points under different conditions, the effect of external conditions on coal spontaneous combustion can be obtained [32]. According to the TG-DTG curve of thermogravimetric analysis, 7 characteristic temperature points can be obtained. And the TGDTG curve of coal samples from Selian mine in air atmosphere is displayed in Figure 4.

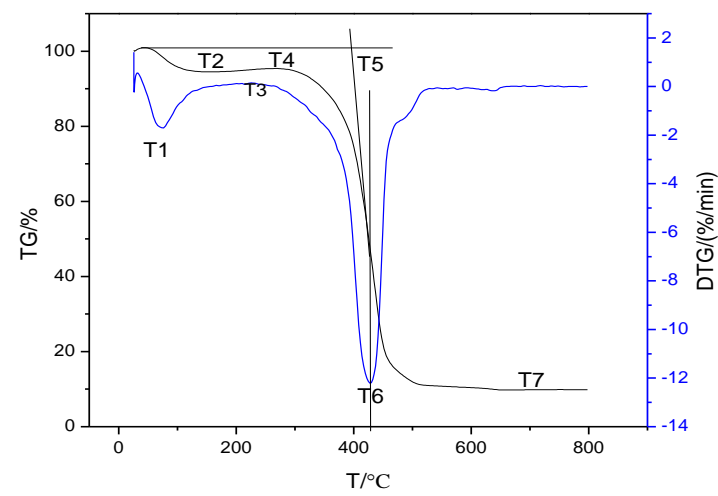

Figure 4. TG-DTG spectrum of the coal from Selian mine

According to Figure 4, the oxidation of coal in air atmosphere can be divided into three stages, which are: the physical and chemical coal oxidation gases desorption weightlessness stage $\left(30{ }^{\circ} \mathrm{C}\right.$ to $180{ }^{\circ} \mathrm{C}$, room temperature to dry temperature $\mathrm{T}_{2}$ ), the coal adsorption weight of oxygen in the air phase $\left(180{ }^{\circ} \mathrm{C}\right.$ to $350{ }^{\circ} \mathrm{C}, \mathrm{T}_{2}$ to fire $\left.\mathrm{T}_{4}\right)$, and coal combustion heat decomposition stage $\left(350{ }^{\circ} \mathrm{C}\right.$ to $700{ }^{\circ} \mathrm{C}, \mathrm{T}_{4}$ to weightlessness temperature of $\mathrm{T}_{7}$ ). The temperature ranges and characteristics of the raw coal samples are given as following:

(1) The critical temperature $\mathrm{T}_{1}\left(60-70{ }^{\circ} \mathrm{C}\right)$ is the temperature where the first maximum weight loss rate reaches. This temperature is also the lowest point of the first weightlessness phase on DTG curve. At this time, the physical adsorption process and desorption process of coal to gas reach a dynamic balance, coal changes from accelerated weightlessness to deceleration weightlessness process

(2) The dry temperature of $\mathrm{T}_{2}\left(140{ }^{\circ} \mathrm{C}\right.$ to $\left.180{ }^{\circ} \mathrm{C}\right)$ is the initial temperature of the side chain functional groups in coal structure are involved in the oxidation reaction. Side chain small molecules gradually break from the main structure of the 
coal, and escape in the form of gas. At this time, ethylene, ethane and others gradually produced, coal samples transit from weightlessness to oxygen increasing stage.

(3) The growth temperature $\mathrm{T}_{3}\left(250-280{ }^{\circ} \mathrm{C}\right)$ is the maximum value where the weight gain rate in the coal oxygen adsorption stage. With the coal gas desorption, the formation of a large number of empty active sites will be formed on the surface of coal, the adsorption capacity of coal to oxygen rises sharply, which is over the amount of gas desorption reaction, the coal sample weight rapid increases. Because the coal surface active site is limited, and the oxidation reaction intensifies gradually. Therefore, the weight gain rate of coal samples is decreased when the temperature reaches $T_{3}$.

(4) Ignition temperature $\mathrm{T}_{4}\left(300-350{ }^{\circ} \mathrm{C}\right)$ is the maximum temperature of coal oxygen mass ratio, which is the end point of coal sample weight gain stage. At this time, as the number of active surface structure of coal increase, the aromatic ring began to participate in the oxidation reaction, which will produce large amounts of $\mathrm{CO}$ and $\mathrm{CO}_{2}$ and other small molecular organic gas, so as to release a lot of heat, then the coal quality will have a sharp decline, it marks the volatiles start to burn, reaching the initial coal combustion temperature.

$(5) \mathrm{T}_{5}$ is $380.01{ }^{\circ} \mathrm{C}$. The initial combustion temperature $\mathrm{T}_{5}$ was obtained by tangent method. That is, in the DTG curve, a vertical is made over the peak $\mathrm{E}$ line to intersect TG curves at a point $F$, then a parallel was made over $F$ to the tangent of TG curve to intersect at the G-spot, then the corresponding temperature of the $\mathrm{G}$-spot is $\mathrm{T}_{5}$.

(6) The temperature $T_{6}$ in situ where the maximum weight loss rate point reaches are $429.75{ }^{\circ} \mathrm{C}$. At this time, a violent chemical reaction occurred inside the coal molecule, the $\mathrm{CO}$ production rate, oxygen consumption rate increased sharply, The rate of heating up sharply, large amount of gas produced, coal sample accelerated weightlessness, but with the consumption of the reactant concentration, the temperature is greater than $\mathrm{T}_{6}$ after deceleration weight loss.

(7) $T_{7}$ is the final temperature of weightlessness, and the final temperature of weight loss is $667.10^{\circ} \mathrm{C}$.

\subsection{Thermal properties of SLC-LDHs materials}

In order to clarify the flame retardant performance of LDHs, LDHs- (1-5) is used as flame retardant, and the method that mechanical grinding method was used to mix with raw coal mixture, so as to prepare SLC-LDHs composite materials with different proportions, what's more, the comparative analysis effect of adding LDHs on the spontaneous combustion tendency of coal was made. Figure 5 shows the effect of different additives on the thermal properties of SLC-LDHs composites.

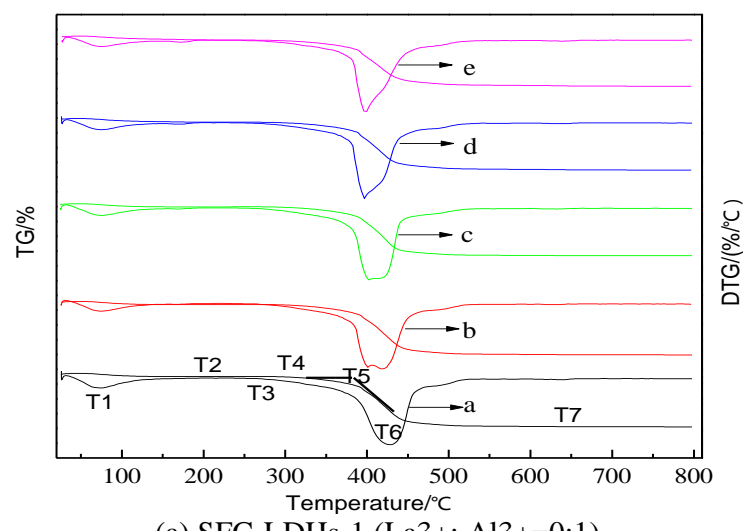

(a) SFC-LDHs-1 (La3+: Al3+=0:1)

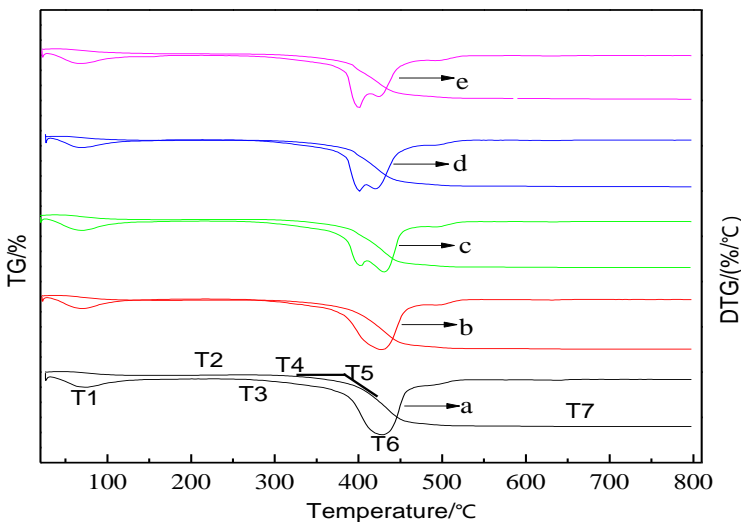

(b) SFC-LDHs-2 (La3+: Al3+=0.1:0.9)

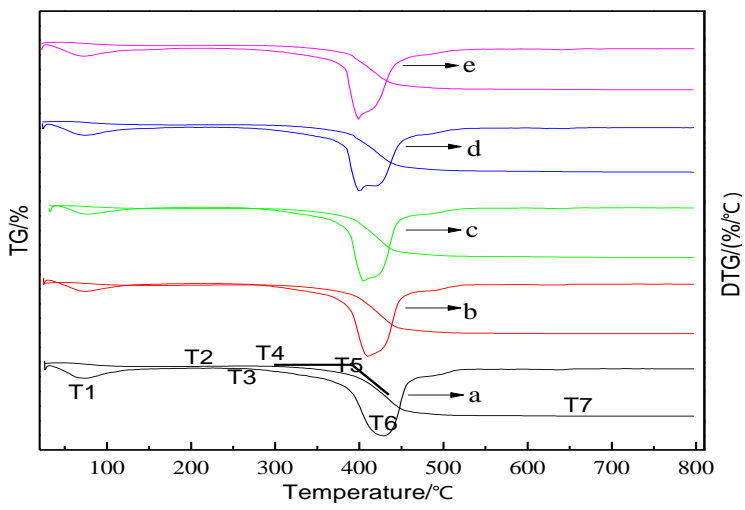

(c) SFC-LDHs-3 (La3+: Al3+=0.3:0.7)

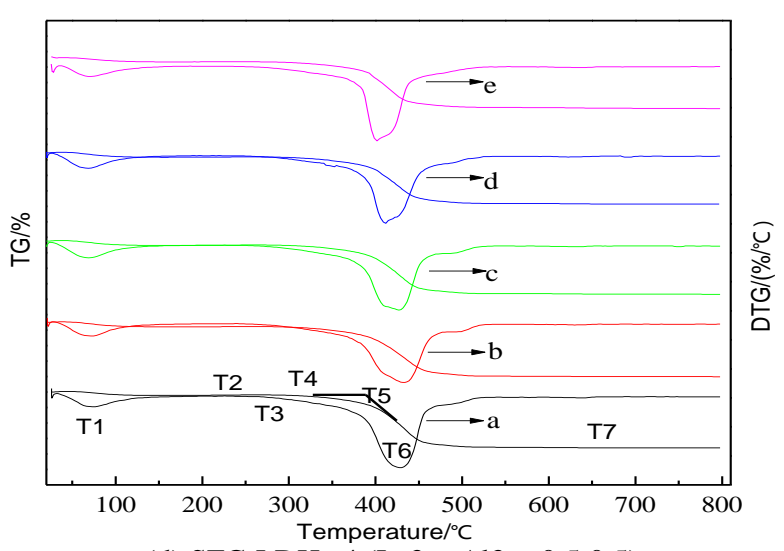

(d) SFC-LDHs-4 (La3+: Al3+=0.5:0.5)

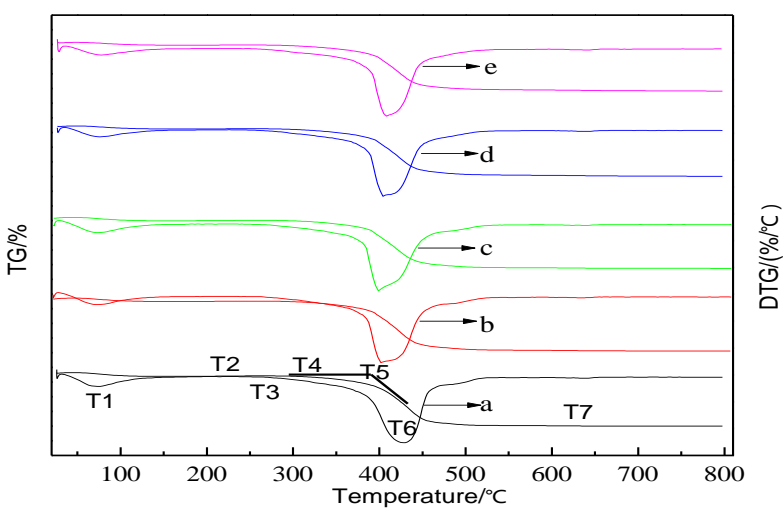

(e) SFC-LDHs-5 (La3+: Al3+=0.7:0.3)

Figure 5. Effect of different additives on thermal stability of various composite materials Additive amount: (a) SLC; (b) $3 \%$; (c) $5 \%$; (d) $10 \%$; (e) $15 \%$ 
It can be seen from Figure 5 that the thermal oxidation process of SFC-LDHs composites is roughly divided into $2 \sim 3$ stages. The first phase starts from room temperature to $170{ }^{\circ} \mathrm{C}$, weightlessness accounted for about $10 \%$ of total weight loss; The second stage is from $180{ }^{\circ} \mathrm{C}$ to $300{ }^{\circ} \mathrm{C}$, LDHs combination of water absorption of heat removal induced weightlessness process and coal oxygen absorption weight gain process happen at the same time. Therefore, when the amount of LDHs is greater than a certain value, (SLC-LDHs) the second stages of composite material gradually change from weight gain stage to weightlessness stage; The third stage is $350{ }^{\circ} \mathrm{C}$ to 600 ${ }^{\circ} \mathrm{C}$, which results severe decomposition and oxidative decomposition, the TG curve decreased significantly, the total weight loss was about $70 \%$, in this stage, the weight loss process caused by the removal of hydroxyl from SLC-LDHs plate and the weight loss process of ignition combustion of coal were simultaneously carried out.

The influence of different LDHs inhibitors on the characteristic temperatures of composite material is shown in Figure 6.

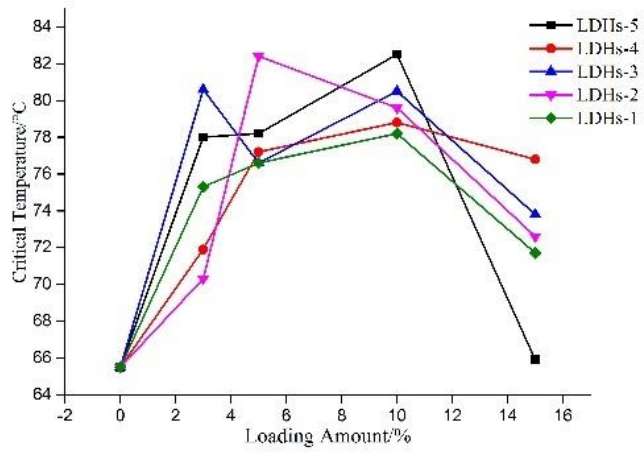

(a) $\mathrm{T}_{1}$

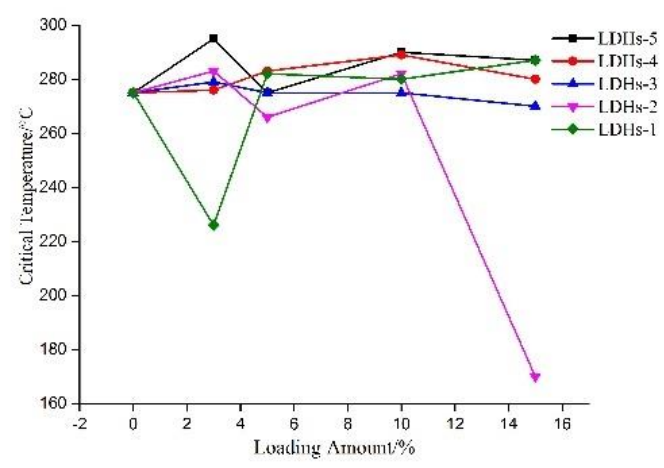

(c) $T_{3}$

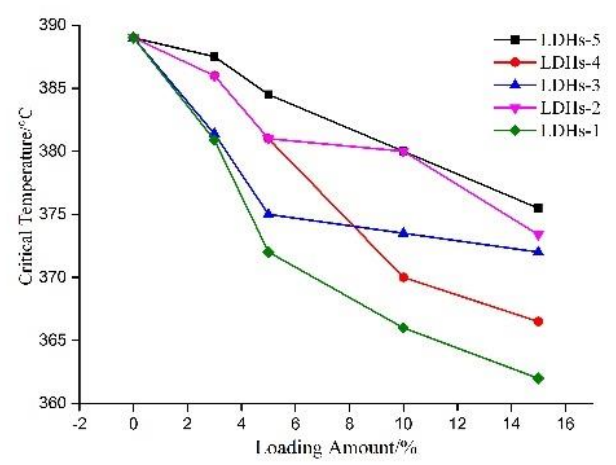

(e) $\mathrm{T}_{5}$

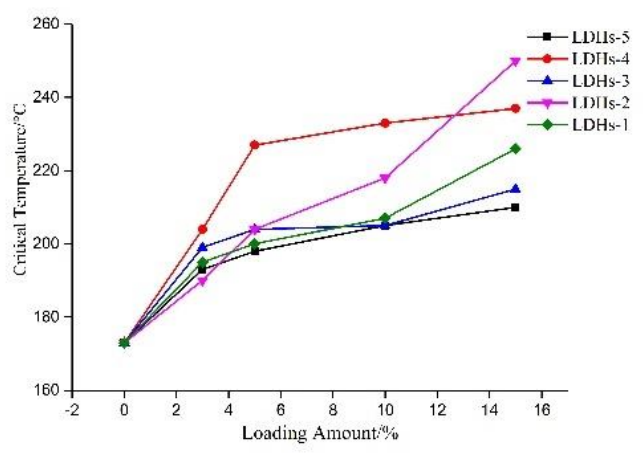

(b) $\mathrm{T}_{2}$

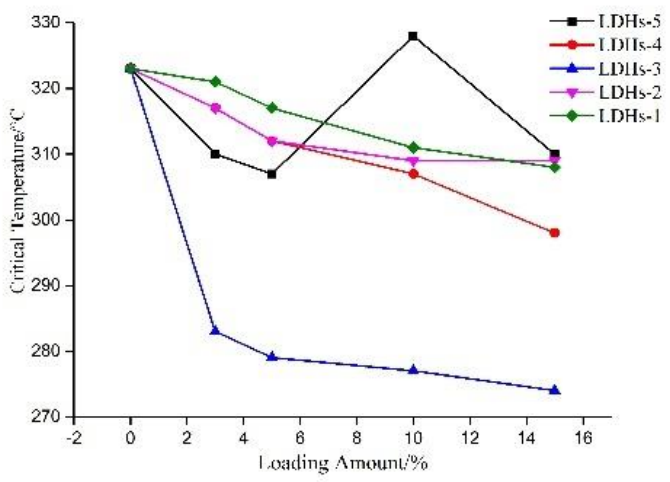

(d) $\mathrm{T}_{4}$

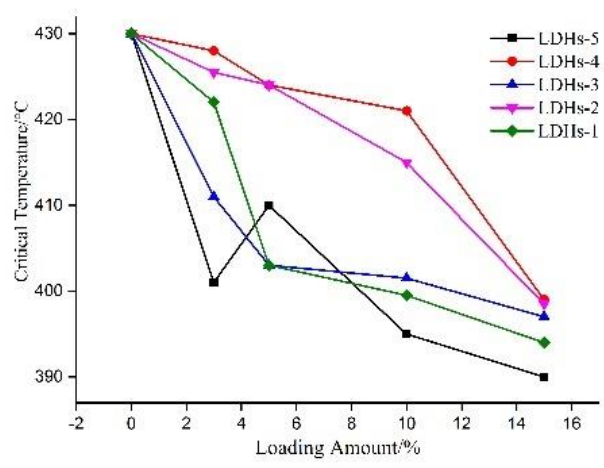

(f) $\mathrm{T}_{6}$

Figure 6. Influence of LDHs inhibitor addition on characteristic temperature point

It can be seen from Figure 6 that 5 kinds of LDHs can cause the critical temperature of coal sample $\mathrm{T}_{1}$ increase, meaning that the endothermic decomposition characteristics of LDHs can lead to lower spontaneous combustion tendency of experimental coal samples. With the increase of LDHs content, the dry temperature of $\mathrm{T}_{2}$ showed a regular increase.

With the increase of LDHs content and disappearance of weight gain stage, the growth temperature $T_{3}$ lost its original physical meaning. Different from raw coal ignition temperature $T_{4}$, characteristic temperature $T_{4}$ of compound material marked the combined action of weightlessness process induced by composite material LDHs absorbing hydroxyl and heavy oxidative loss of condensed aromatic rings in coal macromolecules. With the increase of adding 
amount, 5 kinds of LDHs all led to the decrease of $\mathrm{T}_{4}$ of coal sample, and the order of effect was LDHs-3>LDHs-5>LDHs4> LDHs-2> LDHs-1.

It can be seen from Figure 5e that the characteristic temperature $\mathrm{T}_{5}$ of the five kinds of LDHs and coal composite materials decreased with the increase of adding amount. When adding amount $<15 \%$, the weight loss rate of LDHs-5 was consistent with LDHs at $\mathrm{T}_{5}$, which was LDHs-1>LDHs$4>$ LDHs-3 $>$ LDHs- 2 . When adding amount $>15 \%$, the effect of LDHs on the ignition temperature $\mathrm{T}_{5}$ of coal was not correlated with the weight loss rate of LDHs at $\mathrm{T}_{5}$. Therefore, when the amount of LDHs when the addition amount $>15 \%$, the effect of LDHs could be attributed to the change of $\mathrm{T}_{5}$ with the amount of added material. In the process of thermal decomposition, LDHs can absorb some of the heat needed for coal oxidation, then it can release $\mathrm{CO}_{2}, \mathrm{H}_{2} \mathrm{O}$ and other diluted air oxygen concentration, which can play a certain role in flame retardant, and the endothermic decomposition of LDHs helps to prevent the formation of carbon barrier layer, the initial decomposition temperature of $\mathrm{T}_{5}$ decreases.

The characteristic temperature $\mathrm{T}_{6}$ decreases with the increase of LDHs content, showing that LDHs participate in and promote the formation of coal flame retardant carbon layer, LDHs-5 effect is more significant.

\subsection{Mechanism of LDHs inhibiting coal spontaneous combustion}

The spontaneous combustion process of coal is the exothermic reaction of coal in air, the heat in the coal body cannot timely and effectively transfer to the environment, which causes coal body heat accumulated, and the temperature increased, so as to meet the conditions of coal combustion, then to cause spontaneous combustion of coal [33-34].

LDHs has special physical and chemical characteristics, the inhibiting mechanism of coal spontaneous combustion can be analyzed from its own characteristics. The physical and chemical properties of the material include: (1) the valence electron layer structure of rare earth element atoms has many empty orbitals, which can easily accept the lone pair electrons provided by multiple ligands to form coordination bonds, which makes $\mathrm{La}^{3+}$ possess excellent chelating properties; (2) LDHs contained the largest proportion of element $\mathrm{O}$, reaching to $66.44 \%$, mainly in the interlayer between $\mathrm{CO}_{3}{ }^{2-}$ and interlayer water. With the increase of $\mathrm{La}^{3+}$, the content of element $\mathrm{O}$ in LDHs increased, meaning the increase of the binding water increased.

Therefore, we put forward the following hypothesis: (1) active groups in coal form complexes with metal ions in the inhibitor LDHs; (2) due to the selective complexation of coal macromolecules in $-\mathrm{COOH}$ and $\mathrm{Zn}^{2+}, \mathrm{Mg}^{2+}, \mathrm{Al}^{3+}$ and the adsorption equilibrium of coal to metal ions, $\mathrm{La}^{3+}$ had early adsorption and complexation to the active groups in coal than $\mathrm{Zn}^{2+}$ and $\mathrm{Al}^{3+}$; (3) the addition of $\mathrm{La}^{3+}$ has obvious influence on the structure and morphology of layered double hydroxide. Different rare earth layered double hydroxides, because the $\mathrm{La}^{3+}$ content is different, it may form different complexes with acidic functional groups on coal surface, hence showing different resistance to the performance.

Based on the above assumptions and physicochemical properties of LDHs, the coupling mechanism of adsorption and complexation equilibrium between coal macromolecules and LDHs is proposed, as shown in Figure 7.

The mechanism of restraining spontaneous combustion of coal is presented in Figure 7. On the one hand, because of the inter layer water and inter layer water and plates adsorb anions, LDHs can not only obstruct the diffusion of oxygen to the coal surface, but also absorb the low temperature oxidation of coal generated heat when it is covered or adsorbed on the coal surface; On the other hand, when LDHs removed inter layer water, water evaporation took away the heat generated by coal oxidation, thus it slowed down the coal body temperature, so as to achieve the effect of preventing spontaneous combustion of coal. By adjusting the proportion of LDHs metal ions, initial decomposition temperature of LDHs component can be adjusted prior to the ignition temperature of the coal, it might participate in and promote the formation of carbon barrier layer, and release the $\mathrm{CO}_{2}, \mathrm{H}_{2} \mathrm{O}$ gas, which can further play the role of dilution oxygen concentration and combustion heat, so, it will play a certain flame retardant effect, and slow down fires spread.

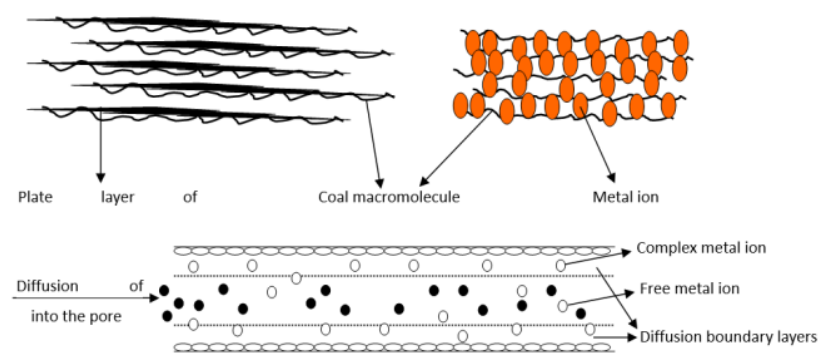

Figure 7. Sketch of adsorption / complexation of coal macromolecules with LDHs metal ions

\section{CONCLUSIONS}

(1) Thermogravimetric analysis is an important method to study the mechanism of coal spontaneous combustion, the TGDTG curve measured by this technique can reflect the physical, chemical adsorption and chemical reaction process of coal oxygen compound process. Among them, TG curve can reflect the change of coal weight caused by coal -oxygen complex and desorption and escape of various gases, DTG curve can reflect the relationship between coal oxygen compound rate and various gas producing rates.

(2) When adding LDHs into coal samples by simple mechanical grinding, and the LDHs-1, LDHs-2, LDHs-3, LDHs-4, LDHs-5 add amount were $3 \%, 5 \%, 10 \%$ and $15 \%$, the critical temperature of colored coal was higher, which could prevent coal spontaneous combustion better.

(3) LDHs can be used as the inhibitor of coal spontaneous combustion. When the physical mixing quantity was $15 \%$, it has good effect on prevention of coal spontaneous combustion.

(4) The coupling regulation mechanism of adsorption and complexation equilibrium between coal macromolecule and LDHs was proposed. on the one hand, due to excellent chelating properties of rare earth elements, selective complexation of coal macromolecules in $-\mathrm{COOH}$ and $\mathrm{Zn}^{2+}$, $\mathrm{Mg}^{2+}, \mathrm{Al}^{3+}$ and the desorption equilibrium of coal to metal ions, $\mathrm{La}^{3+}$ preferentially occurs complexation with $\mathrm{Zn}^{2+}, \mathrm{Mg}^{2+}, \mathrm{Al}^{3+}$ and other active groups in coal complexation, it can stop the reaction between coal and oxygen; On the other hand, with the addition of $\mathrm{La}^{3+}$, the binding water of the intermediate layer of double layered double hydroxide increases, and in heating process, LDHs will multistage decomposition process and absorb more heat, so as to restrain spontaneous combustion of coal." 


\section{REFERENCES}

[1] Wen, H., Guo, J., Jin, Y.F. (2016). Progress and trend of evaluation study on coal mine thermodynamic disasters in China. Safety in Coal Mines, 47(3): 172-174. 10.13347/j.cnki.mkaq.2016.03.047

[2] Ministry of land and resources of the people's republic of China. Report on Mineral Resources in China, 2014.

[3] Niu, H.Y., Deng, X.L., Li, S.L. (2016). Experiment study of optimization on prediction index gases of coal spontaneous combustion. Journal of Central South University, 23(9): 2321-2328. http://doi.org/10.1007/s11771-016-3290-y

[4] Jin, Y.F. (2013). Study on the dynamic evolution mechanism and control of coal seam outcrop fire. Xi'an, Xi'an University of Science and Technology.

[5] Tan, B., Niu, H.Y., He, C.N. (2013). Goaf coal spontaneous combustion temperature field theory and numerical analysis under mining conditions. Journal of Central South University (Science and Technology), 44(1): 381-387.

[6] Deng, J., Xu, J.C., Chen, X.K. (2003). Perspectives on spontaneous combustion mechanism and prediction theory of coal. Journal of Liaoning Technical University, 22(4): 455-459. http://doi.org/10.3969/j.issn.10080562.2003.04.009

[7] Tan, B., Zhu, H.Q., Wang, H.Y. (2014). Combustion state and surface temperature field evolution of closed firing zone in top-coal caving region of coal drift. Journal of Central South University (Science and Technology), 45(3): 946-951

[8] Peng, B.X. (1980). The mechanism of coal spontaneous combustion inhibitor and resistance. Journal of China Coal Society, 3: 38-47.

[9] Liu, J.B. (2002). Flame retardant mechanism analysis of coal and application of chloride vapor fog inhibitor. Journal of North China Institute of Science and Technology, 4(2): 8-10.

[10] Shan, Y.F., Wang, J.R., Deng, C.B. (2008). Study on influences of different inhibitors on coal spontaneous combustion. Journal of Liaoning Technical University (Natural $\quad$ Science), 27(1): 1-4. http://doi.org/10.3969/j.issn.1008-0562.2008.01.001

[11] Chan, X.H., Wang, D.M., Shi, G.Q. (2013). Experiment analysis of high sulfur coal spontaneous combustion inhibition technology in goaf. Journal of Central South University (Science and Technology), 44(5): 2118-2123.

[12] Qin, B.T., Zhang, L.L. (2013). Experimental studies on preparation of multi-phase foamed gel for preventing spontaneous combustion of coal. Journal of Central South University (Science and Technology), 44(11): 4652-4657.

[13] Zheng, L.F. (2009). Experimental study on performance that retarder inhibits coal oxidation and spontaneous combustion. Xi'an, Xi'an University of Science and Technology, 17(3): 326-330 http://doi.org/10.1007/s12404-011-0319-6

[14] Xu, J.C. (1992). Application of colloid fire extinguishing technology in Yangquan NO.2 coal mine. Mining Safety \& Environmental Protection, 2: 43-44.

[15] Deng, J., Xu, J.C. (2001). Technology and application of new type composite colloid fire prevention and extinguishing. Safety in Coal Mines, 12: 42-44. http://doi.org/10.3969/j.issn.1003-496X.2001.12.017
[16] Meng, X.L., Zhu, R.Z., Wu, G.G. (2009). Lab preparation and performance study on polyvinyl alcohol oxygen insulation gel to prevent coal spontaneous combustion. Coal Engineering, 12: 102-105.

[17] Yu, S.J., Yu, M.G., Xie, F.C. (2010). An inorganic foaming gel for preventing spontaneous combustion in a top-coal falling region. Journal of China University of Mining \& Technology, 39(2): 173-177. http://doi.org/10.1016/S1876-3804(11)60004-9

[18] Qian, P., Qin, Z.P., Guo, H.X. (2012). Sodium silicate /polyelectrolyte composite gel material and its performance as spontaneous combustion inhibitor. Industrial Safety and Environmental Protection, 38(8): 13-16. $\quad \mathrm{http} / / /$ doi.org/10.3969/j.issn.1001425X.2012.08.005

[19] Nalawade, P., Awar, B.E., Kadam, J.V. (2009). Layered double hydroxides: A review. Journal of Scientific \& Industrial Research, 68(4): 267-272.

[20] Nyambo, C., Wilkie, C.A. (2009). Layered double hydroxides intercalated with borate anions: Fire and thermal properties in ethylene vinyl acetate copolymer. Polymer Degradation and Stability, 94(4): 506-512. http://doi.org/10.1016/j.polymdegradstab.2009.02.001

[21] Matusinovic, Z., Feng, J.X., Wilkie, C.A. (2013). The role of dispersion of LDH in fire retardancy: The effect of different divalent metals in benzoic acid modified LDH on dispersion and fire-retardant properties of polystyrene-and poly(methyl-methacrylate)-LDH-B nanocomposites. Polymer Degradation and Stability, 98(8): $1515-1527$ http://doi.org/10.1016/j.polymdegradstab.2013.04.007

[22] Xu, S.L., Zhang, L.X., Lin, Y.J. (2012). Layered double hydroxides used as flame retardant for engineering plastic acrylonitrile-butadiene-styrene (ABS). Journal of Physics and Chemistry of Solids, 73(12): 1514-1517. http://doi.org/10.1016/j.jpcs.2012.04.011

[23] Manzi, C., Hossenmlopp, J.M., Wilkie, C.A. (2009). Comparative study on the flammability of polyethylene modified with commercial fire retardants and a zinc aluminum oleate layered double hydroxide. Polymer Degradation and Stability, 94(1): 782-788.

[24] Zhang, Y. (2011). Preparation and flame retardancy of nanocrystalline rare earth-containing layered double hydroxides. Ha'erbin, Northeast Forestry University.

[25] Chen, T.H., Fan, M.D., Qing, C.S. (2005). Structural evolution of heating treatment of $\mathrm{Mg} / \mathrm{Al}-\mathrm{LDH}$ and preparation of mineral mesoporous materials. Acta Petrologica Et Mineralogica, 24(6): 522-525. http://doi.org/10.3969/j.issn.1000-6524.2005.06.005

[26] Xu, J.C. (2001). Coal spontaneous combustion dangerous area decision theory. Beijing: Coal Industry Publishing House.

[27] Zhang, Y.N. (2012). Study on the microcosmic characteristics and macro parameters in the process of coal oxidation and spontaneous combustion. Xi'an, Xi'an University of Science and Technology, http://doi.org/10.7666/d.d223642.

[28] Wu, Q., Chen, W.S. (2008). The thermogravity analysis study on the spontaneous combustion of coal. Journal of Safety Science and Technology, 4(1): 71-73. http://doi.org/10.3969/j.issn.1673-193X.2008.01.016

[29] Zhang, Y.N., Deng, J., Wen, H. (2011). TG/DTG research on spontaneous combustion characteristic temperature of coal sample of Hua-ting mine. Journal of 
Xi'an University of Science and Technology, 31(6): 659662. 9315.2011.06.004 http://doi.org/10.3969/j.issn.1672-

[30] Xiao, Y., Ma, L., Wang, Z.P. (2007). Research on characteristic temperature in coal spontaneous combustion with thermal gravity analysis method. Coal Science and Technology, 35(5): 73-76. http://doi.org/10.1016/S1872-5813(07)60008-5

[31] Zhu, H.Q., Guo, A.D., Qu, L.N. (2012). Experimental study on the relationship among the coal kinetics parameters, characteristic temperatures and volatile. China Safety Science Journal, 22(3): 55-60. http://doi.org/10.3969/j.issn.1003-3033.2012.03.009
[32] Xiao, Y., Wang, Z.P., Ma, L. (2008). Research on correspondence relationship between coal spontaneous combustion index gas and feature temperature. Coal Science and Technology, 36(6): 47-51.

[33] Jin, Y.F., Guo, J., Wen, H. (2015). Experimental study on the high temperature lean oxygen oxidation combustion characteristic parameters of coal spontaneous combustion. Journal of China Coal Society, 40(3): 596-602. http://doi.org/10.13225/j.cnki.jccs.2014.0626

[34] Guo, J. (2014). Study on oxidation combustion characteristic parameters of coalfield fire area under high temperature and lean oxygen. Xi'an, Xi'an University of Science and Technology. 